\title{
Enhancement of the Early/Precise Diagnosis Based on the Measurement of SUVs in F-18 FDG PET/CT Whole-body Image
}

\author{
Jeong-Kyu Park*, Sung Kyu Kim ${ }^{\dagger}$, Ihn-Ho $\mathrm{Cho}^{\ddagger}$, \\ Eun-Jung Kong ${ }^{\ddagger}$, Myeong-Hwan Park*, Bok-Yeon $\mathrm{Cho}^{\S}$ \\ *Department of Radiologic Technology, Daegu Health College, Daegu, Departments of \\ ${ }^{\dagger}$ Radiation Oncology, ${ }^{\ddagger}$ Nuclear Medicine, Yeungnam University College of Medicine, Daegu, \\ ${ }^{\S}$ Department of Radiology, Soonchunhyang University of Hospital Gumi, Gumi, Korea
}

\begin{abstract}
Through this research, we measure the data for several SUVs such as SUVLBM, SUVBW, and SUVBSA using volume of interest in order to enhance the diagnostic level in whole-body image for healthy examinees via F-18 FDG PET/CT. Maximum value, mean value, standard deviation, and threshold value for each SUVs are shown. The measurement of SUVs are carried out with 31 examinees who have taken whole-body examination with F-18 FDG PET/CT from July, 2012 to August, 2012. To secure the preciseness of measurement, we selected 26 healthy examinees as a subject of measurement according to diagnostic view of a nuclear-medical doctor. We see from the measurement of SUVs of PET/CT that the value of SUVBW is hightest and followed by SUVLBM and SUVBSA in turn regardless of the use of contrast media. By comparing the SUVLBM-maximum data for the group used contrast media with those for the group used no contrast media, there found a trend that the measured values increase when the contrast media are used. Among them, liver, aorta, lumbar-5, and Cerebellum exhibit significant difference $(p<0.05)$. We conclude that our data for SUVs would be basic references in overall image interpretation, and hope that the research using VOI would be active.
\end{abstract}

Key Words: F-18 FDG PET/CT, VOI, SUVs, Contrast media

\section{서 론}

PET/CT 검사는 우리 몸의 신진대사에 이용되는 포도당 과 유사한 물질을 주사해 전신의 대사상태의 미세한 변화 를 영상화 시키고 이러한 집적기전의 특이적 현상을 바탕 으로 인체 및 조직 내의 생리적 지표들을 정량적으로 측정 할 수 있다. 병변 및 정상조직의 생화학 변화작용 또는 병 리 현상의 규명과 질병진단, 치료 후 예후 판정, 치료계획 등에 유용하게 이용되고 이러한 장점들은 다른 진단학적 장비의 특성과 비교하였을 경우 상대적으로 많은 정보를 제공 할 수 있다. ${ }^{1)}$

임상에서 PET/CT 검사의 적용은 초기에 알츠하이머병, 파킨슨씨병, 간질과 같은 뇌신경계 질환의 진단에 주로 이

이 논문은 2013년 8월 12일 접수하여 2013년 9월 4일 채택되었음.

책임저자 : 김성규, (705-717) 대구시 남구 대명동 317-1

영남대학교 의과대학 방사선종양학교실

Tel: 053)620-3373, Fax: 053)624-3599

E-mail:skkim3@ynu.ac.kr
용되었으나 최근의 연구들은 폐암, 식도암, 두경부암, 임파 종, 유방암, 갑상선암, 자궁암, 췌장암, 위암, 대장암, 뇌종 양과 같은 암 및 악성 종양들의 조기진단, 병기결정, 치료 효과 판정, 재발의 발견 및 예후 예측 등으로 발전, 확대 적용하고 있는 추세이다. ${ }^{2-5)} \mathrm{PET} / \mathrm{CT}$ 검사에서는 질환의 상 태와 종양의 섭취 및 치료반응을 평가하기 위해 표준화 섭 취계수(standardized uptake values, SUVs)를 사용하는데 SUV는 피검자의 체형(지방조직의 양), 혈중 포도당 농도, 종양의 크기, 정상조직의 섭취 증가, 방사성 동위원소 투여 량과 촬영간격, 관심영역(region of interest, ROI) 등의 영향 을 받고 이를 이용하여 조직에 집적된 방사능 농도를 반 정 량적으로 수치화 한 것이며 현재 임상에서 폭넓게 적용하고 있다. ${ }^{6,7)}$

전신 PET/CT는 종양검사에서 주로 사용하므로 종양조직 에 섭취가 많이 일어나는 방사성 의약품을 사용한다. 여기 에는 조직의 포도당 대사를 반영하는 F-18 FDG (Fluorodeoxyglucose: FDG), 아미노산 대사를 반영하는 C-11 Methionine, 그리고 세포 증식능을 평가할 수 있는 F-18 Fluorothymidine 등이 있다. 이중에서 F-18 FDG가 실제 임상에서 
가장 널리 사용되고 있다. ${ }^{8,9)}$

F-18 FDG의 섭취는 정상조직을 이해하는데 SUVs의 다 양성이 있어야 한다. ${ }^{10)}$ 많은 연구자는 생물학적이나 물리 적인 인자를 관심영역의 크기를 설정하여 SUV 방정식으로 계산하는 광범위한 연구를 진행해 오고 있다. ${ }^{11)}$

관심영역 설정에 따라 평균치와 최대치가 차이를 보이므 로 종양의 악성 정도를 평가하는 경우에는 섭취가 가장 강 한 부위에 ROI를 설정하여 평가한다. ${ }^{12)}$ 최근 많은 연구자 들은 몸무게(body weight, BW), 신체 표면적(body surface area, BSA), 제 지방 몸무게(lean body mass, LBM) 등을 그 인자의 기준으로 연구하고 있으며, ${ }^{13,14)}$ 이중 환자 개개인의 $\mathrm{LBM}$ 을 이용하여 SUV를 측정하는 방법이 가장 정확하다 고 보고되고 있다. ${ }^{14)}$ 또한, SUV 측정 시 3 차원 부피정보가 더욱 정확한 데이터를 제공하지만, 아직 관심부피(volume of interest, VOI)를 이용하여 연구한 결과가 아직 학계에 보 고되지 않았다. 그러므로 PET/CT에서 3차원적 VOI를 이용 한 SUVs의 연구가 필요하다.

본 연구에서는 $\mathrm{SUVs}$ 로 정상부위에서 $\mathrm{SUV}_{\mathrm{LBM}}, \mathrm{SUV}_{\mathrm{BW}}$, $\mathrm{SUV}_{\mathrm{BSA}}$ 를 각각 측정하여 VOI를 이용한 기초 자료를 확보 하고자 하였으며, 궁극적으로 종양과 염증 등 병변에 대한 조기/정밀 진단수준을 향상하고자 한다. 특히, PET/CT에서 조영제를 사용하지 않았던 군과 조영제를 사용한 군의 차 이를 통계학적으로 비교 분석하고자 한다.

\section{1. 조사 대상}

\section{재료 및 방법}

2012년 7월부터 8월까지 전신 F-18 FDG PET/CT 전신 검 사를 시행한 총 31 명을 대상으로 SUVs를 측정 하였다. 본 연구는 임상시험위원회(institutional review board: IRB)의 승 인을 얻었으며, 측정의 정확도를 높이고자 핵의학 전문의 의 소견으로 이중에서 26 명의 건강한 수검자를 대상으로 하였다. 이들은 남자가 6 명, 여자가 20명이었다. 나이는 35 세에서 75 세로 평균연령은 52.5 세였다. 신장은 $145 \mathrm{~cm}$ 에서 $177 \mathrm{~cm}$ 로 평균 신장은 $160.0 \mathrm{~cm}$, 체중은 $40 \mathrm{~kg}$ 에서 $76 \mathrm{~kg}$ 까 지 평균 체중은 $57.8 \mathrm{~kg}$, 조영제를 투여하지 않은 사람은 10 명, 투여한 사람은 16 명이었다.

\section{2. 방법}

1) $\mathrm{PET} / \mathrm{CT}$ 영상 획득: 검사자들은 검사 전 최소한 6시 간을 금식하였고, F-18 FDG 주사 직전 측정한 혈당치가 $180 \mathrm{mg} / \mathrm{dl}$ 이하일 때 주사하였다. F-18 FDG $8.14 \mathrm{MBq} / \mathrm{kg}$ 를
정맥 주사하고 60 90분 후 PET/CT (Discovery VCT, GE Milwaukee, USA)를 이용하여 영상을 획득하였다. 머리에서 근위대퇴까지 45 초간 감쇠보정용 CT (두께: $3.75 \mathrm{~mm}, 140$ $\mathrm{kVp}, 120 \mathrm{~mA}$ ) 영상을 먼저 얻은 후, $\mathrm{CT}$ 스캔과 같은 범위 의 방출영상을 3D-mode로 하여 한 bed 당 3분씩 7 9 bed 를 얻었다. PET 영상은 배열된 부분집합 기대값 최대치화 (ordered subsets expectation maximization method, OSEM) 알 고리즘방식으로 재구성하였으며 CT 영상을 이용하여 감쇠 보정 하였다.

2) 데이터 획득 과정: PET 데이터는 감쇠보정 되었으며, $\mathrm{OSEM}$ 방식으로 재구성되었다. 감쇠 지도(attenuation maps) 는 PET/CT 스캐너의 후처리 소프트웨어 도구를 이용한 기 존의 방식에서 두 개의 선에 의한 CT 데이터로부터 획득 하였다. 정확하지 않은 정합(registration)은 SUVs의 정량화 에 심각한 문제를 발생시킬 수 있으므로 본 연구에서 사용 한 감쇠보정 인자(an attenuation correction factor)는 배경 (background) $0.1 \mathrm{~cm}^{-1}$, 폐(lung) $0.018 \mathrm{~cm}^{-1}$, 지방(fat) 0.086 $\mathrm{cm}^{-1}$, 연부조직(soft tissue) $0.1 \mathrm{~cm}^{-1}$ 이었다. 이러한 감쇠보정 은 PET 영상을 재구성하는데 사용되었다.

3) 영상 분석: CT 데이터, PETAC_CT는 워크스테이션으 로 전송되었다(Syngovia-3D Fusion, Siemens Medical Solution, Erlangen, Germany). Syngovia에 등록된 모든 영상은 자 동 평가되고, 필요하면 개별적(local)으로 수동으로 조절할 수 있다. PET/CT의 정량화 능력을 평가하기 위하여 $3 \mathrm{D}$ Fusion MM Oncology를 이용하여 모니터에 관상면(coronal plane), 시상면(sagittal plane), 횡단면(transverse plane)을 각 각 나타내었다. 횡단면 영상에 VOI의 해부학적 위치는 관 련 문헌을 참조하였고, ${ }^{15)}$ 핵의학 전문의의 도움을 받아 선 정하였다.

간(segment $6,3 \mathrm{~cm}^{3}$ ), 비장(splenic hilum, $2 \mathrm{~cm}^{3}$ ), 대동맥 (췌장부위, $1.5 \mathrm{~cm}^{3}$ ), 골수(허리뼈 1, 2, 3 body center, $1 \mathrm{~cm}^{3}$ ), 허리뼈 5 (상종 판에서 양극 다열근 내, $1 \mathrm{~cm}^{3}$ ), 소뇌(정중 앙, $2 \mathrm{~cm}^{3}$ )를 선정하여 그렸으며 두 개의 선으로 관상면, 시상 면, 횡단면에서 부피의 해부학적 위치를 일치시켰다(Fig. 1).

SUVs는 LBM, BW, BSA를 이용하여 정상조직 내의 VOI 를 각각 최대치(maximum), 평균치(mean), 표준편차(standard deviation, SD), 역치(threshold)로서 평가하였다. SUVs에서 치밀골의 영향으로 뇌를 제외하며, 조영제의 사용 때문인 잠재적인 위험성을 우려하고 있어, ${ }^{16)}$ 본 연구에서는 소뇌 를 포함해 측정하였으며, PET/CT에서 조영제의 사용도 허 용하였다. 종양에 대한 PET 응답기준(PET Response Criteria in Solid Tumors: PERCIST)에서는 최고치(peak)를 권고하나 

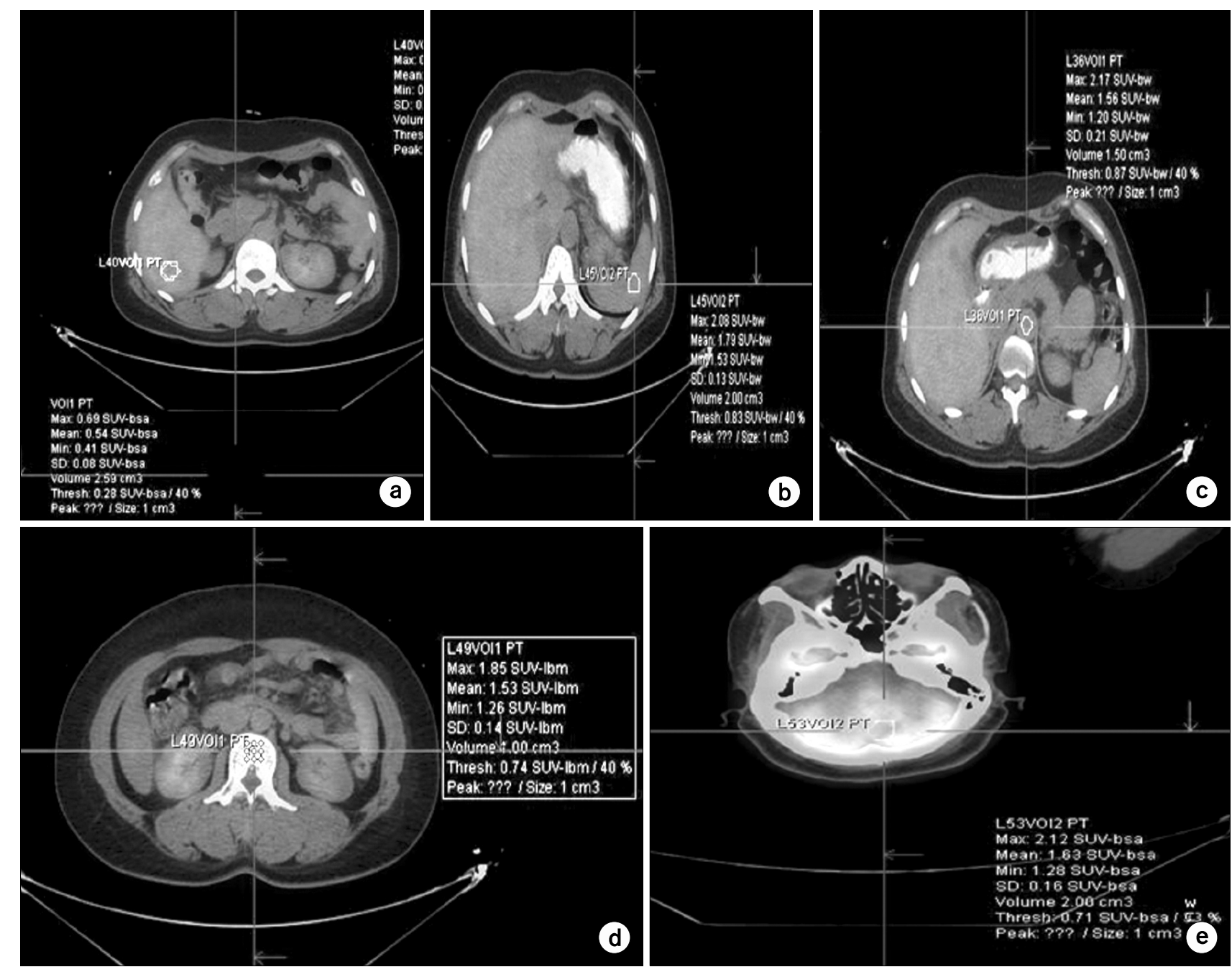

Fig. 1. Measurements of SUVs in the PET/CT.

정상조직에서는 측정되지 않았다. ${ }^{15}$

측정하고자 하는 부위에 해당하는 부피를 설정하면 SUVs최대치는 자동 측정되었으며, 평균 $40 \%$ isocontour VOI에 의해 계산되었다.

4) 통계 분석: 모든 자료의 통계 분석은 윈도용 SPSS 소 프트웨어(SPSS Inc, version 20.0)를 이용하여 시행하였다. $\mathrm{PET} / \mathrm{CT}$ 에서 $\mathrm{SUV}_{\mathrm{LBM}}, \mathrm{SUV}_{\mathrm{BW}}, \mathrm{SUV}_{\mathrm{BSA}}$ 의 최대치, 평균치, 표 준편차, 역치를 빈도분석 하였다.

PET/CT에서 조영제를 사용하지 않은 군과 조영제를 사 용한 군의 비교는 대응표본 t-test를 실시하였다. 모든 통계 분석에서 $\mathrm{p}$ 값은 0.05 미만인 경우에만 통계적으로 유의한 것으로 인정하였다.

\section{결 과}

\section{1. 조영제를 미사용한 $\mathrm{PET} / \mathrm{CT}$ 의 SUVs 측정}

조영제를 사용하지 않았던 $\mathrm{PET} / \mathrm{CT}$ 를 수행한 건강 검진 자들의 SUVs 측정치를 각각 빈도 분석하였다. 성별은 남자 가 2명, 여자가 8명이었으며, $\mathrm{SUV}_{\mathrm{LBM}}, \mathrm{SUV}_{\mathrm{BW}}, \mathrm{SUV}_{\mathrm{BSA}}$ 로 분 류하여 Table로 제시하였다. 조영제를 사용하지 않았을 때 $\mathrm{PET} / \mathrm{CT}$ 의 SUVs 측정에서 $\mathrm{SUV}_{\mathrm{BW}}$ 가 측정치가 가장 높았으 며, $\mathrm{SUV}_{\mathrm{LBM}}, \mathrm{SUV}_{\mathrm{BSA}}$ 순으로 나타났다(Table 1).

\section{2. 조영제를 사용한 PET/CT의 SUVs 측정}

조영제를 사용하여 $\mathrm{PET} / \mathrm{CT}$ 를 수행한 건강 검진자들의 

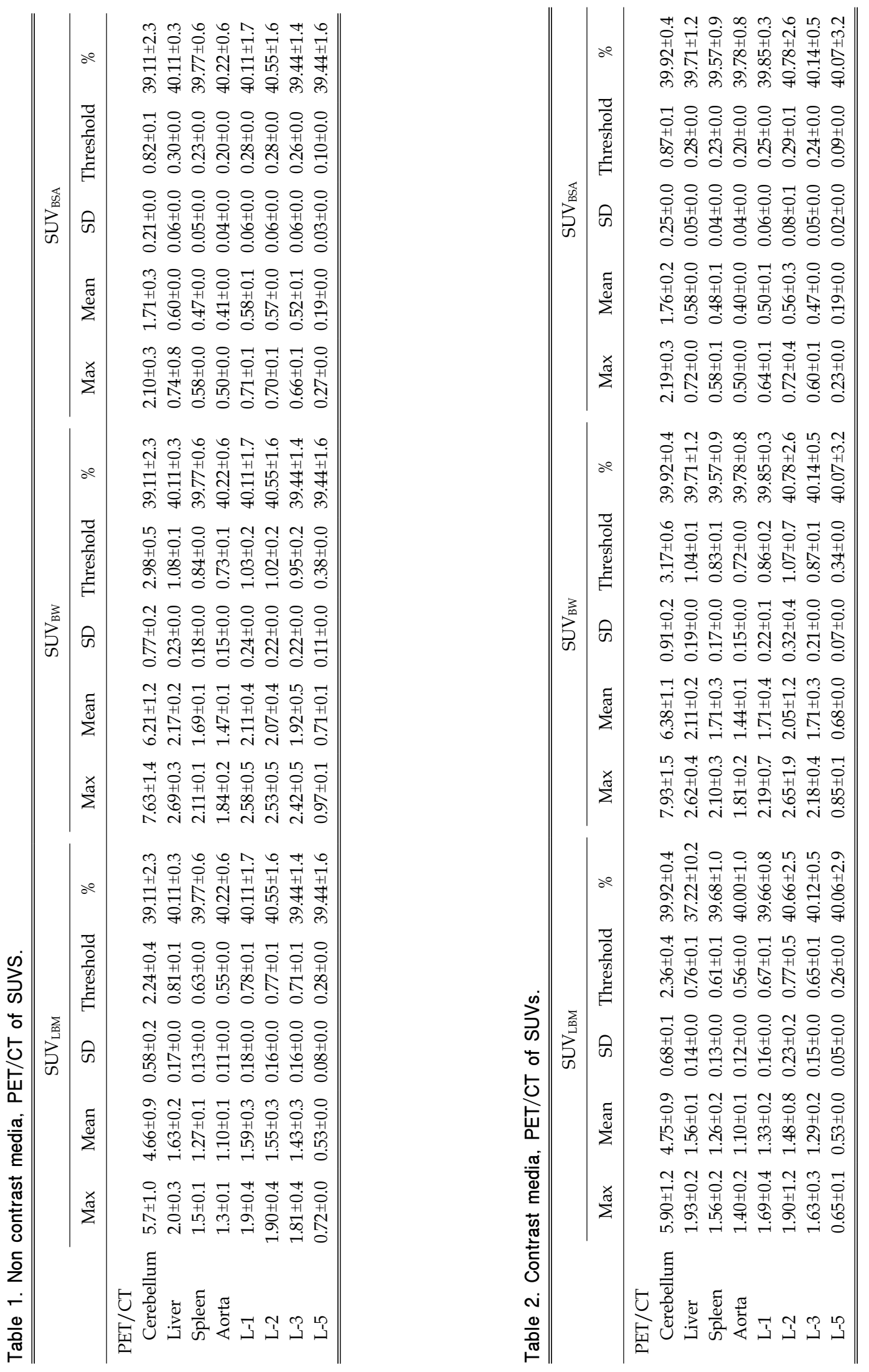
Table 3. Paired samples test of SUV LBM-maximum.

\begin{tabular}{|c|c|c|c|c|c|c|c|c|c|}
\hline & & \multicolumn{8}{|c|}{ Paired differences } \\
\hline & & \multirow{2}{*}{ Mean } & \multirow{2}{*}{ SD } & \multirow{2}{*}{$\begin{array}{c}\text { Std. } \\
\text { error mean }\end{array}$} & \multicolumn{2}{|c|}{$95 \%$ confidence interval of the difference } & \multirow{2}{*}{$\mathrm{t}$} & \multirow{2}{*}{$\mathrm{df}$} & \multirow{2}{*}{$\begin{array}{c}\text { Sig. } \\
\text { (2-tailed) }\end{array}$} \\
\hline & & & & & Lower & Upper & & & \\
\hline Pair1 & CM-Liver & -0.36000 & 0.60105 & 0.11787 & -0.60277 & -0.11723 & -3.054 & 25 & 0.005 \\
\hline Pair2 & CM-Spleen & 0.03231 & 0.58245 & 0.11423 & -0.20295 & 0.26757 & 0.283 & 25 & 0.780 \\
\hline Pair3 & CM-Aorta & 0.22423 & 0.51760 & 0.10151 & 0.01517 & 0.43330 & 2.209 & 25 & 0.037 \\
\hline Pair4 & CM-L1 & -0.18000 & 0.73771 & 0.14468 & -0.47797 & 0.11797 & -1.244 & 25 & 0.225 \\
\hline Pair5 & CM-L2 & -0.29500 & 1.10355 & 0.21642 & -0.74073 & 0.15073 & -1.363 & 25 & 0.185 \\
\hline Pair6 & CM-L3 & -0.07500 & 0.66106 & 0.12964 & -0.34201 & 0.19201 & -0.579 & 25 & 0.568 \\
\hline Pair7 & CM-L5 & 0.93269 & 0.53849 & 0.10561 & 0.71519 & 1.15019 & 8.832 & 25 & 0.000 \\
\hline Pair8 & CM-Cerebellum & -4.1157 & 1.1612 & 0.22773 & -4.5847 & -3.64675 & -18.073 & 25 & 0.000 \\
\hline
\end{tabular}

CM: contrast media.

SUVs 측정값을 각각 빈도 분석하였다. 성별은 남자가 4명, 여자가 12 명이었으며, $\mathrm{SUV}_{\mathrm{LBM}}, \mathrm{SUV}_{\mathrm{BW}}, \mathrm{SUV}_{\mathrm{BSA}}$ 로 분류하여 표로 제시하였다. 조영제를 사용했을 때 PET/CT의 SUVs 측정에서 $\mathrm{SUV}_{\mathrm{BW}}$ 가 측정치가 가장 높았으며, SUVLBM, SUVBSA 순으로 나타났다.

조영제 사용 유무에 따른 PET/CT의 측정치 차이를 비교 해 본 결과 전체적으로 조영제를 사용했을 때가 SUVS 측 정치가 증가하였다(Table 2).

\section{3. 조영제 사용 유무에 따른 PET/CT의 SUVs의 비교}

조영제를 사용하지 않은 군과 조영제를 사용한 군의 SUV 차이를 비교하기 위하여 $\mathrm{SUV}_{\mathrm{LBM}}$-maximum을 이용하여 대 응 표본 t-test를 실시하였다.

조영제를 사용함으로 인하여 간, 대동맥, 요추-5, 그리고 소뇌의 $\mathrm{SUV}_{\mathrm{LBM}}$-maximum 측정치는 뚜렷하게 차이가 있는 것으로 나타났다 $(\mathrm{p}<0.05)$.

\section{고찰 및 결론}

본 연구에서는 PET/CT에서 정상부위에 VOI를 이용하여 SUVs 데이터를 제시하였다. PET/CT는 많은 경우에서 신생 물의 진행, 뼈의 이상, 폐, 림프샘에서 영상 해석을 정확하 게 기술하였다. ${ }^{17)}$

본 연구와 관련하여 2차원적 $\mathrm{ROI}$ 를 이용한 정상부위의 영상을 평가한 S zincirkeser의 SUVBW-최대치의 연구결과 와 비교하였다. ${ }^{10)}$ 남자는 소뇌 10.5 , 간 5.0 , 비장 4.1 , 대동 맥 3.1, 그리고 허리뼈-1이 5.2로 나타났으며, 여자는 소뇌 10.1 , 간 3.8 , 비장 3.2 , 대동맥 2.9 , 허리뼈-1이 4.5 로 나타났
다. 본 연구에서는 남자는 소뇌 6.5 , 간 2.4 , 비장 1.8 , 대동 맥 1.2 , 그리고 허리뼈-1이 2.5 로 나타났으며, 여자는 소뇌 7.4 , 간 2.6, 비장 2.0 , 대동맥 1.9 , 그리고 허리뼈-1이 2.4로 나타났다. 이는 3 차원적 $\mathrm{VOI}$ 를 이용한 본 연구결과에서 $\mathrm{SUV}_{\mathrm{BW}}$ 가 낮게 나타남을 알 수 있었으며, 더 많은 부위에서 더 많은 SUVs를 측정할 필요성이 제기된다.

본 연구에서는 PET/CT에 조영제 사용유무에 따른 SUVs 의 비교를 $\mathrm{SUV}_{\mathrm{LBM}}$ 최대치를 이용하여 비교하였다. 이는 실 제 연구 중에서 $\mathrm{SUV}_{\mathrm{LBM}}$ 을 이용한 측정을 권고하고 있으며, 병소의 크기가 일정하지 않아 표준섭취계수의 평균값을 구 하면 데이터의 획득 시마다 불안정하므로 SUVs 최대치를 이 용한다고 하였다. ${ }^{12)}$ 이와 관련하여 $\mathrm{SUV}_{\mathrm{LBM}}, \mathrm{SUV}_{\mathrm{BW}}, \mathrm{SUV}$ BSA 의 각 최대치를 포함하여 측정하여 Table로 제시하였다 (Table 3).

SUV는 다양한 요인에 의해 영향을 받으며 영향을 미치 는 요인은 다음과 같다. 우선 먼저 환자의 체격은 몸의 비 중을 1 로 하여 계산하는 방법으로, FDG 섭취가 매우 미약 하고 체지방이 많은 사람에게서는 투여량의 체중보정으로 과 보정될 수 있다. 혈당치의 높고 낮음은 종양의 FDG 섭 취를 방해할 수 있는 요인이 되며, PET에서는 일반적으로 병소가 주위에 비해 높은 섭취를 보이기 때문에 측정대상 의 크기가 공간분해능의 5 배 정도로 충분히 크지 않으면 부분용적효과(partial volume effect, PVE)에 의해 측정된 방 사능이 실제의 방사능보다 낮게 산출된다고 하였다. ${ }^{21}$

SUVs의 데이터가 측정된 8곳의 정상 장기에서는 F-18 $\mathrm{FDG}$ 의 경우 균일하다고는 하나 PET 영상에서 생리적인 상위 역치를 구하기가 어려운 이유로 종양이나 염증의 진 단은 일반적으로 높은 섭취율과 연관되어 진단하는데 한계 
가 있으므로, ${ }^{10)} \mathrm{PET} / \mathrm{CT}$ 에서 위양성과 위음성을 줄이기 위 한 적절한 대책으로 VOI를 이용한 정상부위의 SUVs 데이 타를 알고 있어야 할 것이다. 전신 F-18 FDG PET/CT에서 조영제를 사용하지 않은 군과 조영제를 사용한 군을 비교 했을 때 조영제를 사용함으로 SUVs가 증가하는 양상을 보 이고 있으며, $\mathrm{SUV}_{\mathrm{LBM}}$-최대치를 이용하여 비교했을 경우 8 부위 중 간, 대동맥, 요추-5, 그리고 소뇌는 유의하게 차이 가 있는 것으로 나타났다 $(\mathrm{p}<0.05)$.

$\mathrm{PET} / \mathrm{CT}$ 의 모든 영상의 판독에서 본 SUVs 데이터가 조 기정밀/ 진단 수준을 향상 하는데 기초 자료가 될 것이라 고 판단되며, $\mathrm{VOI}$ 를 이용한 연구가 활발히 이루어지길 기 대한다.

\section{참 고 문 헌}

1. Park SY: Consideration on the satisfaction of patients and Variation according to whether or not to listen to music after F-18 FDG Injection. The Graduate School of Bio-Medical Science, Korea University (2013)

2. Oriuchi N, Higuchi $\mathrm{T}$, Ishikita $\mathrm{T}$, et al: Present role and future prospects of positron emission tomography in clinical oncology. Cancer Sci 97(12):1291-1297 (2006)

3. Hany TF, Steinert HC, Thomas F: Integrated PET/ CT: current applications and future direction. Radiology 238:(1) 405-422 (2006)

4. Benamor M, Ollivier L, Brisse H, Moulin R, Servois V, Neuenschwander S: The clinical role of CT/ PET in oncology: an update. Cancer Imaging 5:(8)68-75 (2005)

5. Bar-Shalom R, Yefremov N, Guralnik L, et al: Clinical performance of PET/CT in evaluation of cancer: additional value for diagnostic imaging and patient management. The Journal of Nuclear Medicine 44:(9)1200-1209 (2013)

6. Weber WA: Positron emission tomography as an imaging biomaker. J Clin Oncol 24(20):3282-3292 (2006)
7. Czernin J, Allen M, Schelbert R: Improvements in cancer staging with PET/CT: Literature based evidence as of September. J Nucl Med 48(1):78-88 (2007)

8. Tian M, Zhang H, Nakasone $Y$, Mogi K, Endo K: Expression of Glut-1 and Glut-3 in untreaed oral squamous cell carcinoma compared with FDG accumulation in a PET study. 31(1):5-12 (2004)

9. Tohma T, Okazumi S, Makino $\mathrm{H}$, et al: Relationship between glucose transporter, hexokinase and FDG-PET in esophageal cancer. Hepato-Gastroenterol 52:(62)486-490 (2005)

10. Zincirkeser S, Şahin E, Halac M, Sageret S: Standardized uptake values of normal organs on 18F-Fluorodeoxyglucose positron emission tomography and computed tomography imaging. J Int Med Res 35:(2)231-236 (2007)

11. Boellaard R: Standards for PET image acquisition and quantitative data analysis. J Nucl Med 50(1):11-20 (2009)

12. Lee HS: A study for distortion of standardized uptake value according to the does and lesion size using 18F-FDG PET/CT. Graduates School Korea Univ (2012)

13. Bushnell D, Madsen M, Menda $Y$, et al: Evaluation of various corrections to the standardized uptake value for diagnosis of pulmonary malignancy. Nucl Med Common 22(1): 1077-1081 (2001)

14. Zasadny KR, Wahl RL: Standardized uptake values of normal tissues at PET with2-[fluorine-18]-fluoro-2-deoxy-D-glucose: variations with body weight and a method for correction. Radiology 189:(1)847-850 (1993)

15. Wahl RL, Jacene $H$, Kasamon $Y$, Lodge MA: From RECIST to PERCIST: evolving considerations for PET response criteria in solid tumors. JNM 50:(1)122-149 (2009)

16. Eiber M, Martinez-Möller A, Souvatzoglou M, et al: Value of a Dixon-based MRI/PET attenuation correction sequence for the localization and evaluation of PET-positive lesions. Eur J Nucl Med Mol Imaging 38:(5)1691-1701 (2011)

17. Boellaard R, O'Doherty Mike J, Weber Wolfgang A, et al: FDG PET and PET/CT: EANM procedure guide-lines for tumour PET imaging: version 1.0. Eur $\mathrm{J}$ Nucl Med Mol Imaging 37:(10)181-200 (2010) 


\title{
F-18 FDG PET/CT 전신 영상에서 SUVs 측정에 기반한 조기/정밀 진단 연구
}

\author{
*대구보건대학교 방사선과, 영남대학교 의과대학 ${ }^{\dagger}$ 방사선종양학교실, ${ }^{\dagger}$ 핵의학교실, \\ §순천향대학교 구미병원 영상의학과

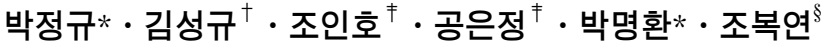

본 연구의 목적은 건강한 검진자들을 대상으로 F-18 FDG PET/CT 전신 영상에서 진단 수준을 향상하고자 관심부피를

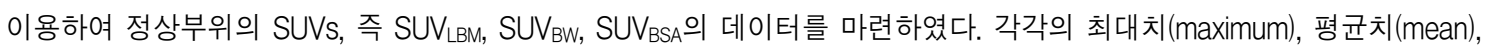
표준편차(standard deviation), 역치(threshold)를 제시 하고자 한다. 2012년 7월부터 8월까지 전신 F-18 FDG PET/CT 검사 를 시행한 총 31 명을 대상으로 SUVs를 측정 하였다. 측정의 정확도를 높이고자 핵의학 전문의의 소견으로 이중에서 26

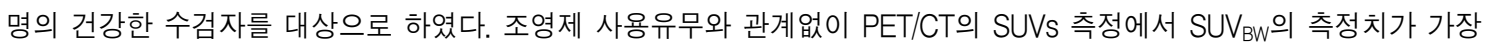
높았으며, SUV $\mathrm{LBM}_{\text {LM }}$ SUV $\mathrm{BSA}_{\text {A }}$ 순으로 나타났다. SUV $\mathrm{LBM}^{-}$최대치를 이용하여 조영제를 사용하지 않은 군과 사용한 군을 비교 했을 경우, 조영제를 사용했을 경우 측정치가 증가하는 경향을 보였으며, 8부위 중 간, 대동맥, 요추-5, 소뇌는 매우 유의 하게 차이가 있는 것으로 나타났다 $(\mathrm{p}<0.05)$. PET/CT의 모든 영상의 판독에서 본 SUVs 데이터가 조기정밀/진단 수준을 향상 하는데 기초 자료가 될 것이라고 판단되며, $\mathrm{VOI}$ 를 이용한 연구가 활발히 이루어지길 기대한다.

중심단어: F-18 FDG PET/CT, 관심부피, SUVs, 조영제 